\title{
Controlled Synthesis of Hollow Hemispheric ZnO Shells/Cages on Graphite Fiber
}

\author{
Xianbin Liu, ${ }^{1}$ Hejun Du, ${ }^{1}$ Zhiyuan Zeng, ${ }^{2}$ and Xiao Wei Sun ${ }^{3}$ \\ ${ }^{1}$ School of Mechanical and Aerospace Engineering, Nanyang Technological University, 50 Nanyang Avenue, Singapore 639798 \\ ${ }^{2}$ School of Materials Science and Engineering, Nanyang Technological University, 50 Nanyang Avenue, Singapore 639798 \\ ${ }^{3}$ School of Electrical and Electronic Engineering, Nanyang Technological University, 50 Nanyang Avenue, Singapore 639798
}

Correspondence should be addressed to Hejun Du, mhdu@ntu.edu.sg

Received 28 February 2011; Accepted 30 March 2011

Academic Editor: I.-C. Chen

Copyright ( $\odot 2011$ Xianbin Liu et al. This is an open access article distributed under the Creative Commons Attribution License, which permits unrestricted use, distribution, and reproduction in any medium, provided the original work is properly cited.

\begin{abstract}
Hollow hemispheric $\mathrm{ZnO}$ shells/cages are synthesized on graphite fiber via simple thermal evaporation process. The cage-like $\mathrm{ZnO}$ structures exhibit micron or submicron size and hollow hemispheric shape with polycrystalline shell made of the $\mathrm{ZnO}$ nanocrystals. Controlled time-sequenced growth experiment is conducted to interpret the growth process, which indicates that the growth mechanism of the hollow hemispheric $\mathrm{ZnO}$ shells/cages involves formation of $\mathrm{Zn}$ particles firstly, followed by oxidation of the outer surface of $\mathrm{Zn}$ droplets and meantime sublimation of the core $\mathrm{Zn}$.
\end{abstract}

\section{Introduction}

Zinc oxide $(\mathrm{ZnO})$ is a good candidate optoelectronic material owing to its direct bandgap and the large exciton energy [1]. Noncentrosymmetric structure-induced piezoelectric behavior makes it possible for electromechanical devices [2]. In addition, $\mathrm{ZnO}$ is biocompatible and biosafe which makes it suitable for biomedical applications [3]. In the past decades, $\mathrm{ZnO}$ nanostructures have been widely studied for electronic, optoelectronic, electrochemical, and electromechanical applications, such as UV lasers [4], light-emitting diodes (LEDs) [5], solar cells [6], sensors [7], and piezoelectric nanogenerators [8]. Significant efforts have been made to obtain desirable morphological nanostructures through various synthesis methods, mainly including thermal evaporation method [9-11], metal-organic chemical vapor deposition (MOCVD) [12,13], pulsed laser deposition (PLD) [14], and aqueous solution methods [15].

Among all available morphologies, hollow cage-like $\mathrm{ZnO}$ structures represent an important category, which may exhibit particular applications for catalyst, sensor, and optoelectronic component owing to their lower densities and higher surface area. However, up to now, synthesis of hollow cage-like $\mathrm{ZnO}$ structures is still a challenge. Recently, cagelike $\mathrm{ZnO}$ structures have also been achieved by different researchers [16-18]. However, the growth mechanism for the cage-like $\mathrm{ZnO}$ structures is still controversial and further investigation is necessary. In this paper, we report the successful synthesis of hollow hemispheric $\mathrm{ZnO}$ shells/cages on graphite fiber using mixtures of $\mathrm{ZnO}$ and graphite powder at $750^{\circ} \mathrm{C}$ in a low pressure. The structures of the hollow $\mathrm{ZnO}$ shells/cages exhibit with rough surface rather than polyhedral profile (as the reports [16-18]). Meanwhile, a detail discussion of the growth mechanism is presented based on a time-sequenced growth experiment.

\section{Experimental Section}

The synthesis of $\mathrm{ZnO}$ shells/cages was carried out in a conventional tube furnace system which we have reported previously [19]. ZnO powder (99.9\%) and graphite powder (99.9\%) with 1:1 mole ratio were mixed and loaded into an alumina boat. The mixture was placed at the center of the quartz tube. A bundle of graphite fibers with average diameter of $7 \mu \mathrm{m}$ was put on a silicon substrate and loaded downstream $(16-18 \mathrm{~cm})$ from the centre, where the temperature is $\sim 750^{\circ} \mathrm{C}$. The tube was heated to $1100^{\circ} \mathrm{C}$ and kept for special times. The furnace pressure is $2.5 \times 10^{-2}$ Torr with constant Ar flow at $50 \mathrm{sccm}$ and $\mathrm{O}_{2}$ flow at $1 \mathrm{sccm}$. After 


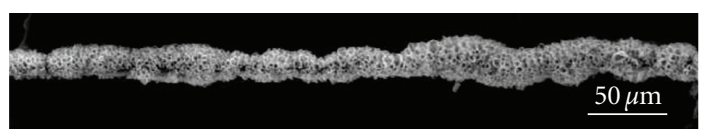

(a)

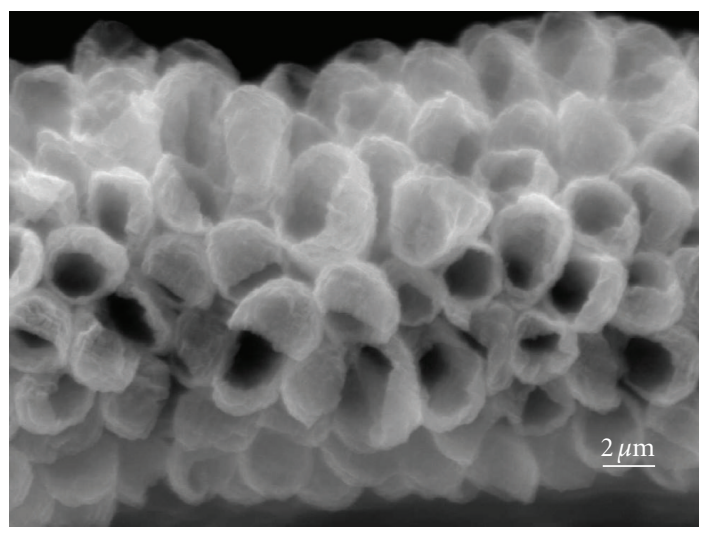

(b)

FIgUre 1: (a) A typical low-magnification SEM image of the asgrown honeycomb-like $\mathrm{ZnO}$ cages covered around the graphite fiber. (b) High-magnification SEM image of the hemispheric $\mathrm{ZnO}$ shells/cages with average diameter $2 \mu \mathrm{m}$ stacked together around the graphite fiber.

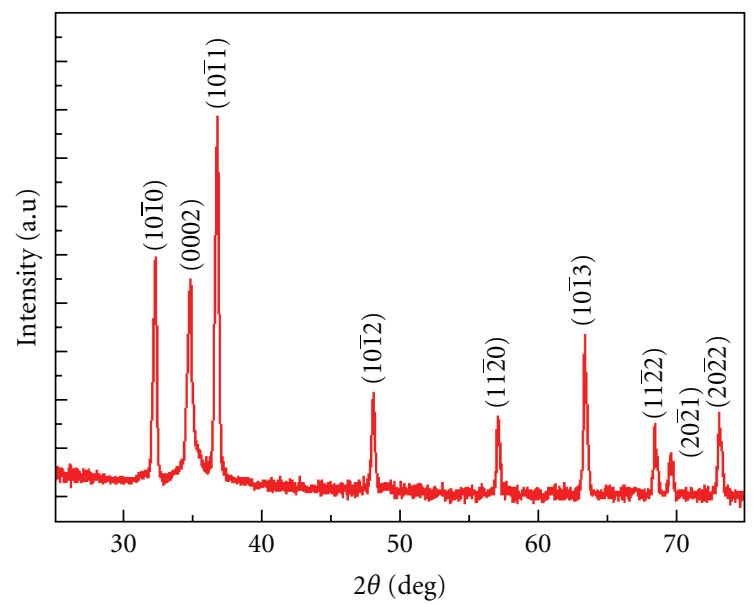

FIgURE 2: XRD pattern of the as-made hemispheric $\mathrm{ZnO}$ shells/cages.

that, the furnace was turned off and we let it cool down to room temperature under Ar flow.

Then scanning electron microscopy (SEM, Hitachi S$3500 \mathrm{~N}$ ) was employed to examine the morphology of the as-made product. The crystal structure of the sample was characterized by X-ray diffraction (XRD) using copper $K_{\alpha 1}$ radiation. High-resolution transmission electron microscope (HRTEM) and electron diffraction patterns were obtained on a JEOL JEM-2010 instrument with operation voltage at $200 \mathrm{kV}$.

\section{Results and Discussion}

After thermal evaporation, it was found that some white products were deposited around the graphite fibers. The

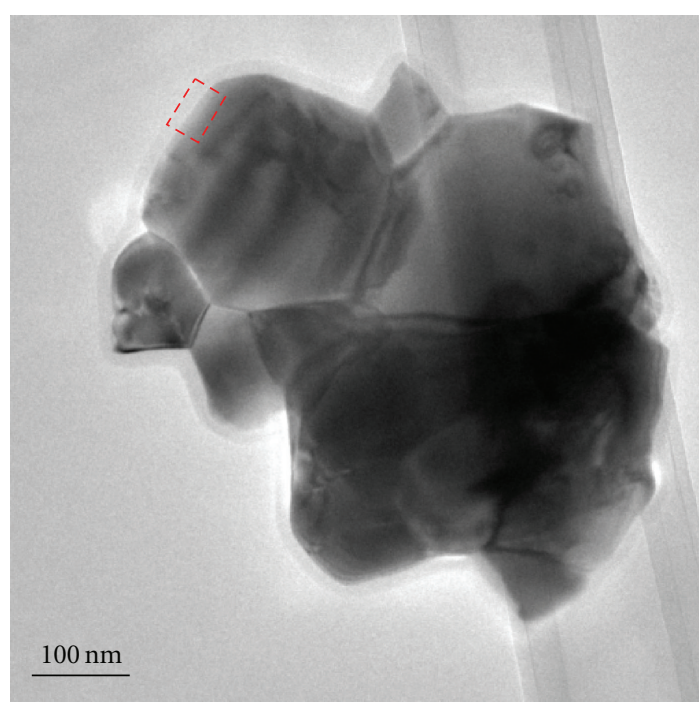

(a)

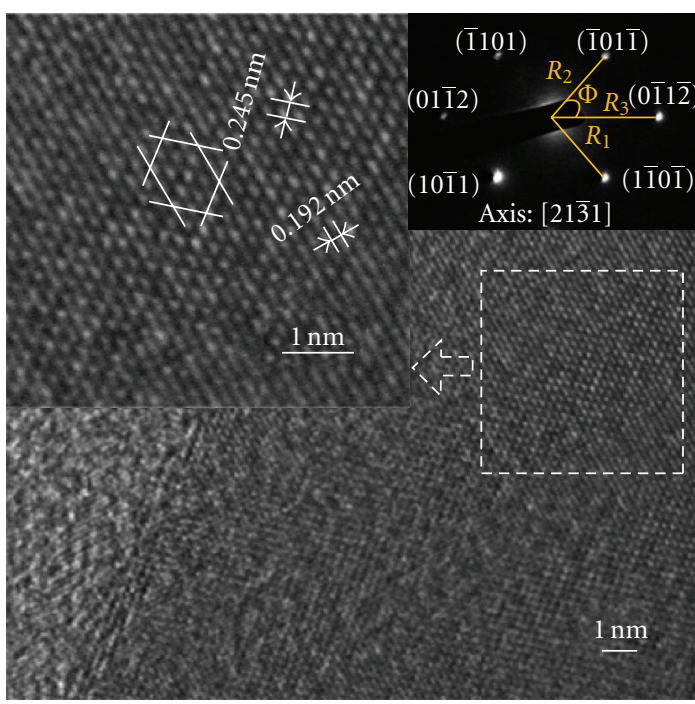

(b)

FIGURE 3: (a) TEM image of the carapace-like $\mathrm{ZnO}$ nanoshell broken from the shell of the hollow $\mathrm{ZnO}$ cages. (b) HRTEM image of the red dashed frame marked in Figure 3(a), the upleft inset is the enlarging image corresponding to the white dashed frame in Figure 3(b), and the upright inset is the SAED pattern on the $\mathrm{ZnO}$ nanoshell.

morphology of the as-synthesized product obtained after thermal evaporation for $40 \mathrm{~min}$ is shown in Figure 1. Figure 1(a) is a low-magnification SEM image which clearly shows that the graphite fiber is covered with honeycomblike products. A high-magnification SEM image is shown in Figure 1(b); it clearly indicates that the honeycomb-like products are made of numerous uniform microsize hemispheric $\mathrm{ZnO}$ shells/cages, which stacked together around the graphite fiber. It shows that the hollow $\mathrm{ZnO}$ microcages are almost hemispherical open with average diameter of about $2 \mu \mathrm{m}$. One point to emphasize is that the above cage-like products are stacked one by one separately, and 


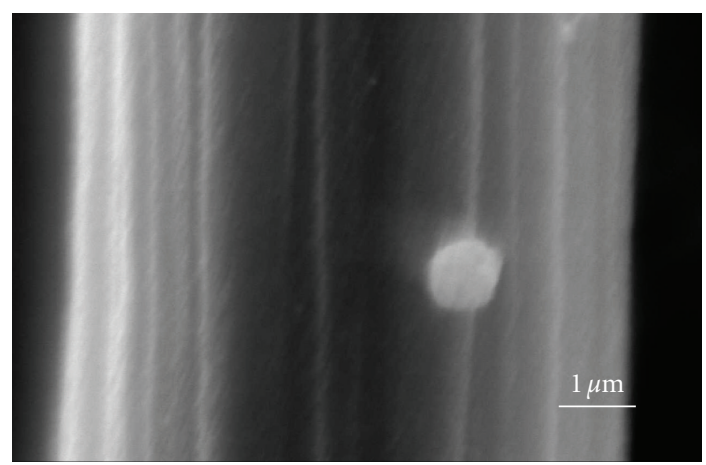

(a)

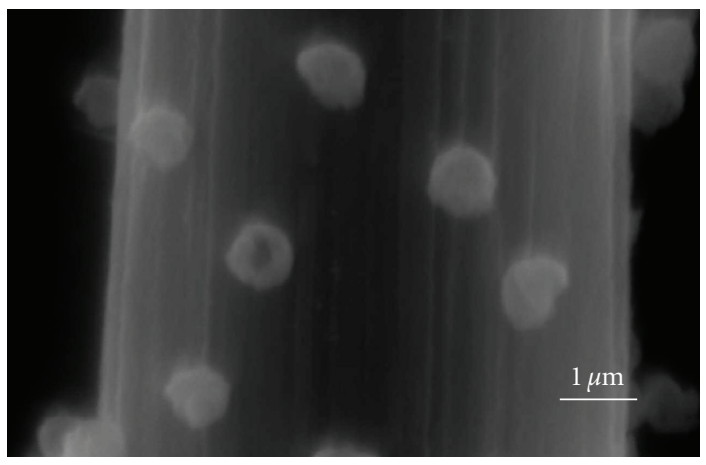

(b)

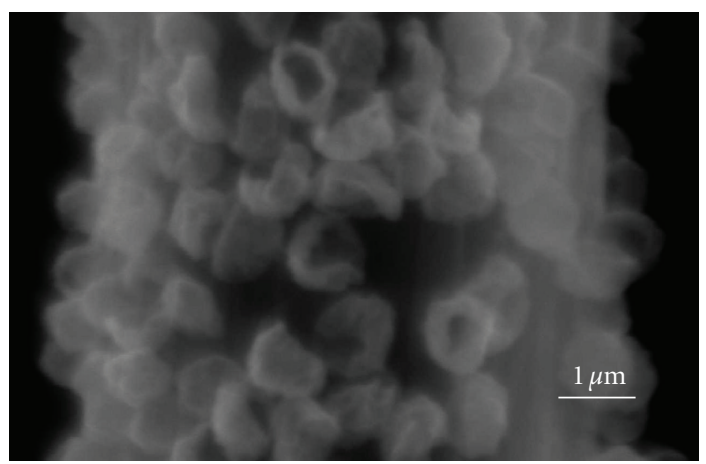

(c)

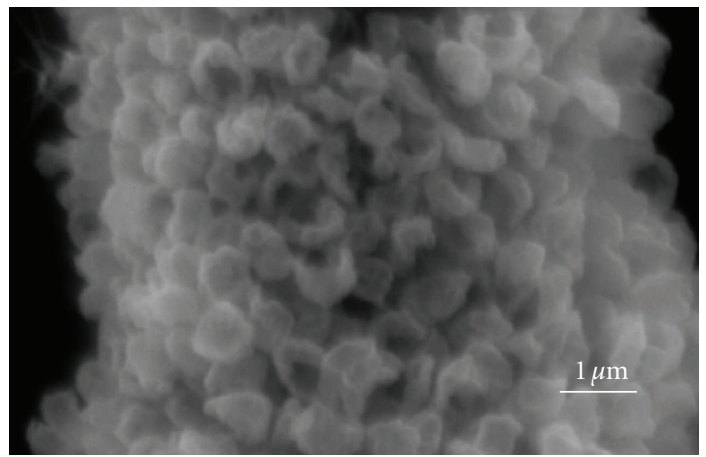

(d)

Figure 4: SEM images representing the growth progress of the hemispheric $\mathrm{ZnO}$ shells/cages. (a) Sample growth less than $1 \mathrm{~min}$. (b) Sample after 3 min growth. (c) Sample after 5 min growth. (d) Sample after $10 \mathrm{~min}$ growth.

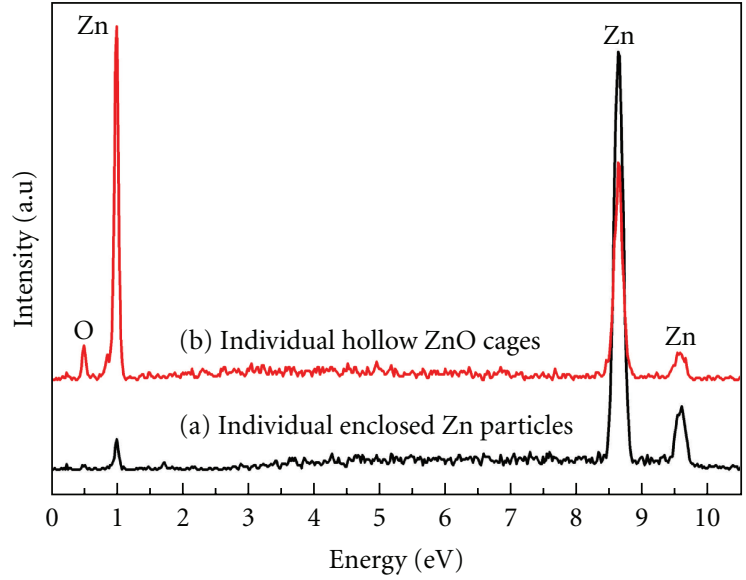

FIgURE 5: EDS spectrum taken from (a) individual enclosed $\mathrm{Zn}$ particles in Figures 4(a) and 4(b) individual hollow $\mathrm{ZnO}$ cages.

almost not hinge joint, which suggests that they nucleated and grew independently to form individual spherical-shaped Zinc liquid droplets [16].

The XRD pattern is illustrated in Figure 2. As indicated in the figure, all diffraction peaks match the wurtzite structural $\mathrm{ZnO}$ (JCPDS card no. 36-1451) with lattice constants $a=$ $3.250 \AA$ and $c=5.207 \AA$. The characteristic diffraction peaks of the as-made $\mathrm{ZnO}$ micro- and nanocages are located at $32.3^{\circ}, 34.9^{\circ}, 36.8^{\circ}$, and $63.4^{\circ}$ which correspond to (1010), (0002), (10ī1), and (10ī3) planes of the wurtzite $\mathrm{ZnO}$, respectively. The result of XRD spectrum indicates that the as-made products are composed of wurtzite $\mathrm{ZnO}$ with good crystallinity.

Further examination of the crystallography and structure of the hollow cage-like structures was carried out by transmission electron microscopy (TEM) as shown in Figure 3. A low-magnification TEM image of a fragment broken from the shell of the hollow $\mathrm{ZnO}$ cages is given in Figure 3(a), which clearly shows that the carapace-like shell of the $\mathrm{ZnO}$ cages is polycrystalline and composed of plentiful nanocrystalline $\mathrm{ZnO}$ slices. Figure 3(b) is HRTEM image recorded from the red dashed frame of the nanoparticle in Figure 3(a). From the upper-left enlargement image shown in Figure 3(b), it can be clearly seen that the atoms arrange regularly to form a sixfold quasisymmetric projected structure. The distances between the lattice fringes are $0.245 \mathrm{~nm}$ and $0.192 \mathrm{~nm}$, corresponding to the $\{10 \overline{1} 1\}$ and $\{10 \overline{1} 2\}$ planes, respectively. Moreover, the selected area electron diffraction (SAED) pattern is also presented in the upper-right inset in Figure 3(b). The distance of the diffraction patterns is measured: $R_{1} / R_{2}=0.99 \approx 1, R_{3} / R_{1}=$ 1.31 , and the included angle between $R_{3}$ and $R_{2}$ is $49.2^{\circ}$, which indicates that the zone axis is [21 31$]$ and the nearest diffraction planes are marked on the SAED pattern (which is consistent with our aforementioned HRTEM results). Herein, it is worth mentioning that the free-standing plane of the $\mathrm{ZnO}$ nanocrystal is $(21 \overline{3} 1)$, not as normally reported

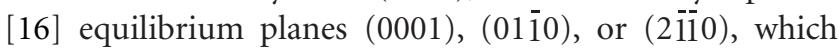




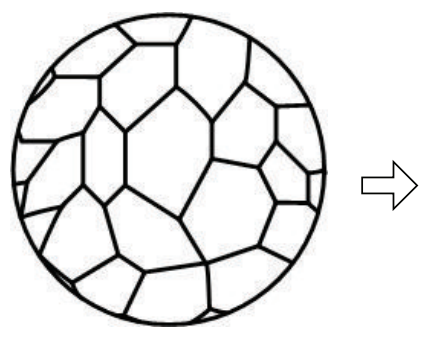

(a)

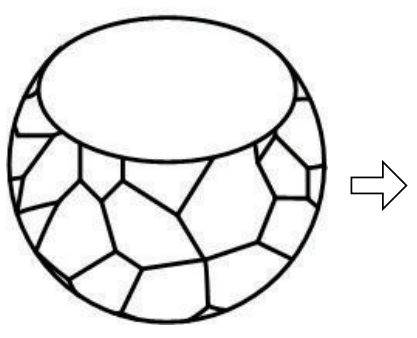

(b)

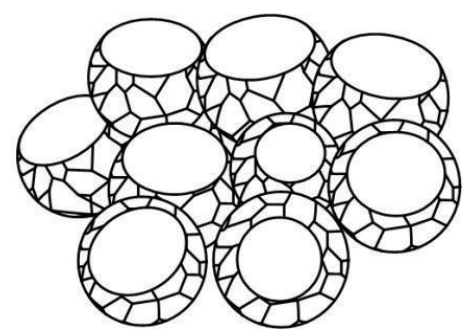

(c)

Figure 6: Schematic diagram of the growth process of the hemispheric $\mathrm{ZnO}$ shells/cages. (a) Vapor $\mathrm{ZnO}_{x}$ reduced into vapor $\mathrm{Zn}$, and $\mathrm{Zn}$ droplets/particles are precipitated on the graphite surface. (b) Zn particles transforming into $\mathrm{ZnO}$ from the outside surface to the core, and meantime $\mathrm{Zn}$ in the core is ready to vaporize at elevated temperature, leaving behind a hollow cage-like ZnO crust. (c) Precipitation, oxidation, and vaporization are undergoing simultaneously during the experiment, and more hollow hemispheric $\mathrm{ZnO}$ shells/cages are formed and stacked together around the graphite fiber.

indicates that the formation process of the hemispheric $\mathrm{ZnO}$ shells/cages is probably nonequilibrium. In our experiment, the hemispheric $\mathrm{ZnO}$ shells/cages were synthesized at $750^{\circ} \mathrm{C}$, which is much higher than the melting point of $\mathrm{Zn}\left(419^{\circ} \mathrm{C}\right)$. Hence, the solidification and oxidation are in the nonequilibrium level and tend to preserve its droplet spherical-shaped [16].

To better interpret the growth mechanism of the cage-like $\mathrm{ZnO}$, time-sequenced growth experiments were carried out. Vapor-liquid-solid (VLS) [20] mechanism and vapor-solid (VS) [21] mechanism have been proposed to be dominant theory for synthesizing $\mathrm{ZnO} 1 \mathrm{D}$ nanostructures via thermal evaporation or vapor transport method. In VLS mechanism, metal catalysts are always used to promote the growth of the nanostructures. Since no metal catalyst has been used in our experiment, the growth process does not follow the VLS mechanism but VS mechanism. Figure 4 shows the SEM results after growth under the same conditions $\left(T_{\text {source }}=\right.$ $1100^{\circ} \mathrm{C}, T_{\text {sub }}=750^{\circ} \mathrm{C}$ ) but different growth times, which clearly exhibits the whole progress during the first growth stage. Figure 4 (a) presents the result after $<1$ min growth, that is, the furnace was shut off immediately when the temperature reached $\left(1100^{\circ} \mathrm{C}\right)$. Only a few closed particles with diameter less than $1 \mu \mathrm{m}$ were found, while the energy dispersive X-ray spectrometer (EDS) spectrum reveals that the chemical composition of the enclosed particles is mainly composed of element $\mathrm{Zn}$ and a little element $\mathrm{O}$ (Figure 5(a)). To clearly illuminate the growth mechanism, the schematic diagram of the growth process is proposed in Figure 6. In the beginning of the growth, vapor $\mathrm{ZnO}_{x}$ passing through the substrate, was reduced into vapor $\mathrm{Zn}$ by the graphite fiber firstly and precipitated into $\mathrm{Zn}$ particles once vapor $\mathrm{Zn}$ is supersaturated (see Figure 6(a)).

After several minutes growth (Figures 4(b)-4(d)), we can see that (1) all the individual hollow $\mathrm{ZnO}$ cages are verified to be $\mathrm{ZnO}$ (Figure 5(b)). (2) All of the particles become hollow $\mathrm{ZnO}$ cages or vacant shells with less than $1 \mu \mathrm{m}$ diameter and tens to hundred nanometers thickness, and almost no closed. (3) The quantity is increased nearly exponentially with growth time increasing. Therefore, it is believed that the precipitated $\mathrm{Zn}$ particles is not stable, which are ready to be oxidized into $\mathrm{ZnO}$ from the outer surface to the center. And at this temperature, the core $\mathrm{Zn}$ also cannot be survived but sublimated, leaving behind hollow cage-like $\mathrm{ZnO}$ crust (Figure 6(b)). During the experiment, precipitation, oxidation, and sublimation are undergoing almost simultaneously and ceaselessly (i.e., in nonequilibrium level), hence more and more hemispheric $\mathrm{ZnO}$ shells/cages are stacked around the graphite fiber (Figure 6(c)). It is necessary to note that a low oxygen partial pressure $\left(2-5 \times 10^{-2}\right.$ Torr in our experiment) is a crucial factor to obtain such hollow cage-like $\mathrm{ZnO}$ structures, which is consistent with Fan's report [17]. We have synthesized wirelike $\mathrm{ZnO}$ nanostructures around graphite fiber at higher pressure [22]. In addition, carbon form graphite fiber may be acted as a significant stabilizer [18] besides its reducing effect, which can be attributed to another ingredient for formation of such cage-like $\mathrm{ZnO}$ structures. From the above results, we propose that reductive atmosphere (low pressure or C stabilizer) to form $\mathrm{Zn}$ or $\mathrm{Zn}$ rich particles firstly is responsible for synthesis of hollow cage-like $\mathrm{ZnO}$ structure.

\section{Conclusions}

Hollow hemispheric $\mathrm{ZnO}$ shells/cages have been synthesized on graphite fiber by simple thermal evaporation process. Through the controlled time-sequenced growth study, a possible growth mechanism of such hemispheric $\mathrm{ZnO}$ shells/cages is proposed as follow: formation of $\mathrm{Zn}$ particles firstly, followed by oxidation of the outer surface of $\mathrm{Zn}$ droplets and meantime sublimation of the core $\mathrm{Zn}$. In summary, formation of $\mathrm{Zn}$ or $\mathrm{Zn}$-rich particles is an indispensable step for successful synthesis of hollow cage-like $\mathrm{ZnO}$ structure.

\section{Acknowledgment}

Xianbin liu gratefully acknowledges the many fruitful discussions about the TEM results with Dr. Zhou Zhaohui (School of Materials Science and Engineering, Beihang University). 


\section{References}

[1] A. B. Djurišić and Y. H. Leung, "Optical properties of $\mathrm{ZnO}$ nanostructures," Small, vol. 2, no. 8-9, pp. 944-961, 2006.

[2] Z. L. Wang, "Nanopiezotronics," Advanced Materials, vol. 19, no. 6, pp. 889-892, 2007.

[3] J. X. Wang, X. W. Sun, A. Wei et al., "Zinc oxide nanocomb biosensor for glucose detection," Applied Physics Letters, vol. 88, no. 23, Article ID 233106, 2006.

[4] S. P. Lau, H. Y. Yang, S. F. Yu et al., "Laser action in $\mathrm{ZnO}$ nanoneedles selectively grown on silicon and plastic substrates," Applied Physics Letters, vol. 87, no. 1, Article ID 013104, 3 pages, 2005.

[5] X. W. Sun, B. Ling, J. L. Zhao et al., "Ultraviolet emission from a $\mathrm{ZnO}$ rod homojunction light-emitting diode," Applied Physics Letters, vol. 95, no. 13, Article ID 133124, 2009.

[6] M. Law, L. E. Greene, J. C. Johnson, R. Saykally, and P. Yang, "Nanowire dye-sensitized solar cells," Nature Materials, vol. 4, no. 6, pp. 455-459, 2005.

[7] L. Liao, H. B. Lu, M. Shuai et al., "A novel gas sensor based on field ionization from $\mathrm{ZnO}$ nanowires: Moderate working voltage and high stability," Nanotechnology, vol. 19, no. 17, Article ID 175501, 2008.

[8] Z. L. Wang and J. Song, "Piezoelectric nanogenerators based on zinc oxide nanowire arrays," Science, vol. 312, no. 5771, pp. 243-246, 2006.

[9] X. Y. Kong, Y. Ding, R. Yang, and Z. L. Wang, "Single-crystal nanorings formed by epitaxial self-coiling of polar nanobelts," Science, vol. 303, no. 5662, pp. 1348-1351, 2004.

[10] Z. W. Pan, Z. R. Dai, and Z. L. Wang, "Nanobelts of semiconducting oxides," Science, vol. 291, no. 5510, pp. 19471949, 2001

[11] B. D. Yao, Y. F. Chan, and N. Wang, "Formation of $\mathrm{ZnO}$ nanostructures by a simple way of thermal evaporation," Applied Physics Letters, vol. 81, no. 4, p. 757, 2002.

[12] W. I. Park, J. Yoo, and G. C. Yi, "Catalyst-free metalorganic chemical-vapor deposition of ultrafine $\mathrm{ZnO}$ nanorods," Journal of the Korean Physical Society, vol. 46, no. 5, pp. L1067L1070, 2005.

[13] Z. Z. Ye, J. Y. Huang, W. Z. Xu, J. Zhou, and Z. L. Wang, "Catalyst-free MOCVD growth of aligned $\mathrm{ZnO}$ nanotip arrays on silicon substrate with controlled tip shape," Solid State Communications, vol. 141, no. 8, pp. 464-466, 2007.

[14] Y. Sun, G. M. Fuge, and M. N. R. Ashfold, "Growth of aligned $\mathrm{ZnO}$ nanorod arrays by catalyst-free pulsed laser deposition methods," Chemical Physics Letters, vol. 396, no. 1-3, pp. 2126, 2004.

[15] J. W. P. Hsu, Z. R. Tian, N. C. Simmons, C. M. Matzke, J. A. Voigt, and J. Liu, "Directed spatial organization of zinc oxide nanorods," Nano Letters, vol. 5, no. 1, pp. 83-86, 2005.

[16] P. X. Gao and Z. L. Wang, "Mesoporous polyhedral cages and shells formed by textured self-assembly of $\mathrm{ZnO}$ nanocrystals," Journal of the American Chemical Society, vol. 125, no. 37, pp. 11299-11305, 2003.

[17] H. J. Fan, R. Scholz, F. M. Kolb, M. Zacharias, and U. Gösele, "Growth mechanism and characterization of zinc oxide microcages," Solid State Communications, vol. 130, no. 8, pp. 517-521, 2004.

[18] L. Castañeda, "Synthesis and characterization of $\mathrm{ZnO}$ microand nano-cages," Acta Materialia, vol. 57, no. 5, pp. 1385$1391,2009$.

[19] B. J. Chen, X. W. Sun, C. X. Xu, and B. K. Tay, "Growth and characterization of zinc oxide nano/micro-fibers by thermal chemical reactions and vapor transport deposition in air," Physica E, vol. 21, no. 1, pp. 103-107, 2004.

[20] R. S. Wagner and W. C. Ellis, "Vapor-liquid-solid mechanism of single crystal growth," Applied Physics Letters, vol. 4, no. 5, pp. 89-90, 1964.

[21] G. W. Sears, "A growth mechanism for mercury whiskers," Acta Metallurgica, vol. 3, no. 4, pp. 361-366, 1955.

[22] X. B. Liu, H. J. Du, B. Liu, J. X. Wang, X. W. Sun, and H. D. Sun, "Fabrication and photoluminescence properties of graphite fiber/ZnO nanorod core-shell structures," Journal of Nanoscience and Nanotechnology, vol. 11, pp. 1-6, 2011. 

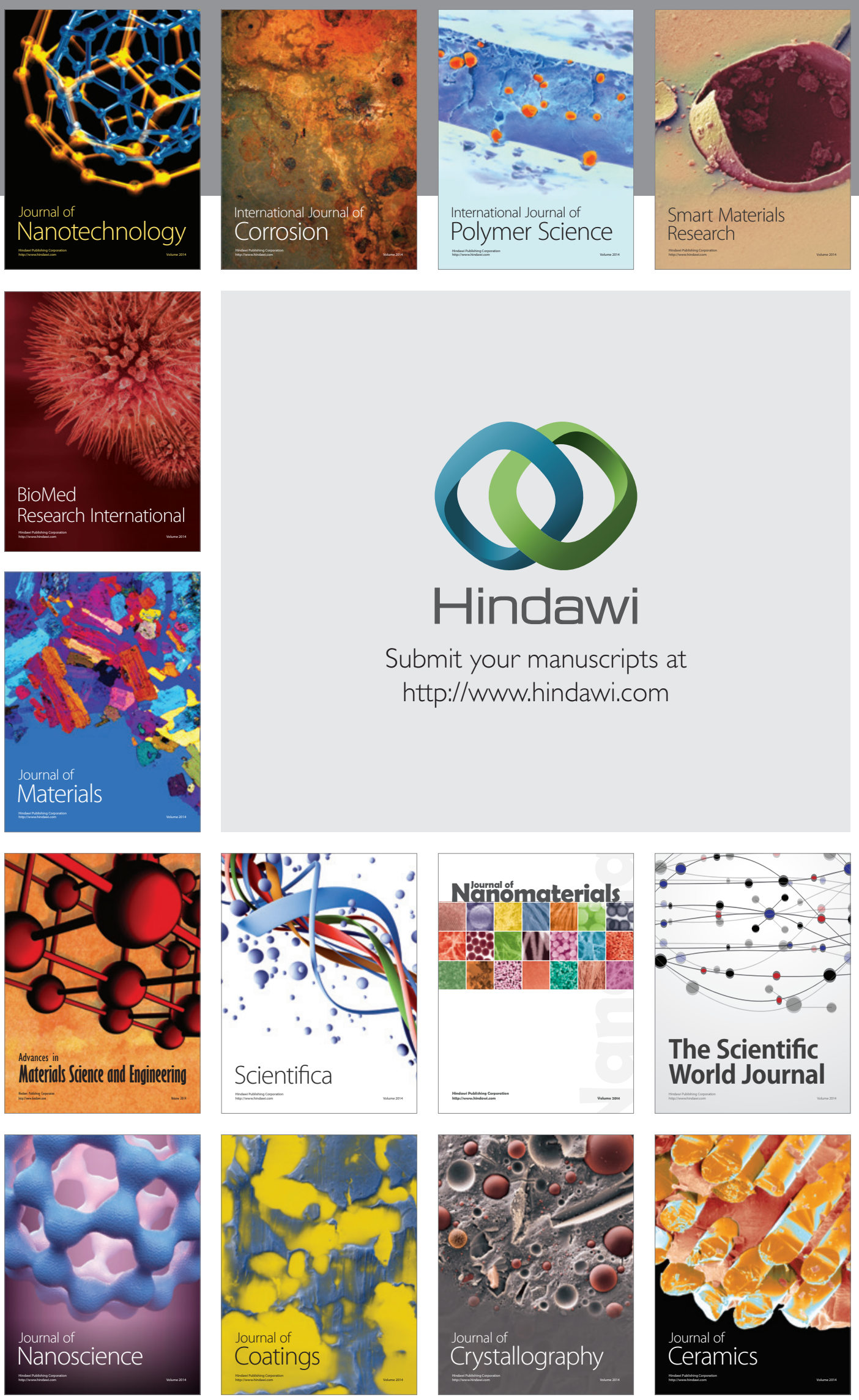

The Scientific World Journal

Submit your manuscripts at

http://www.hindawi.com

\section{World Journal}

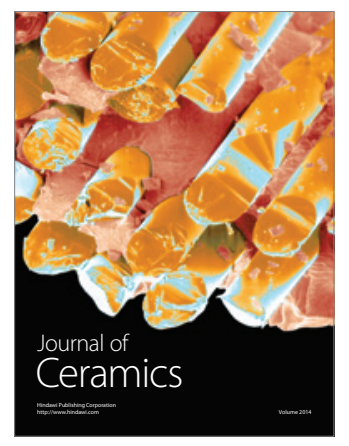

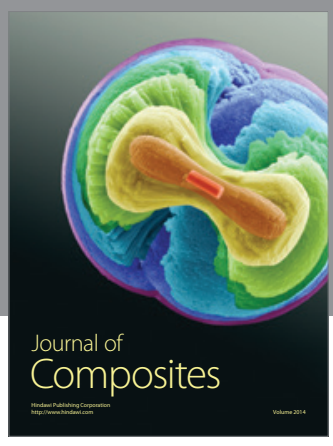
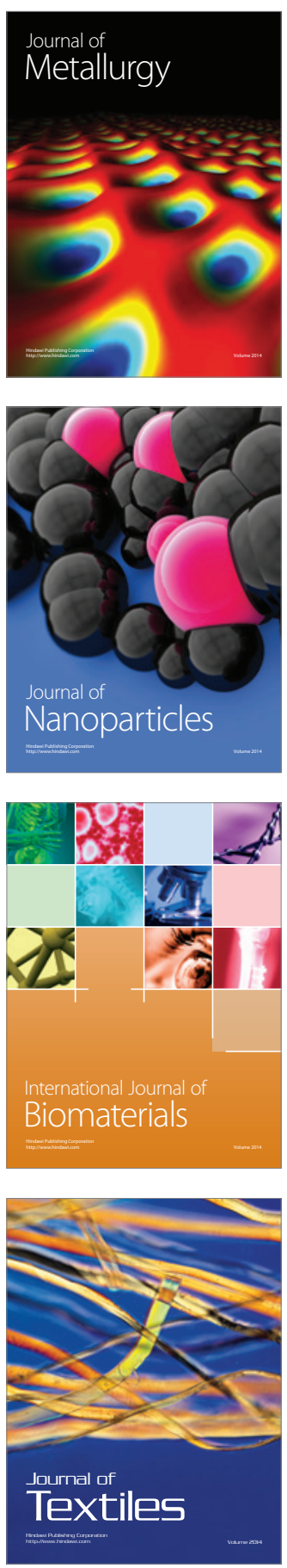